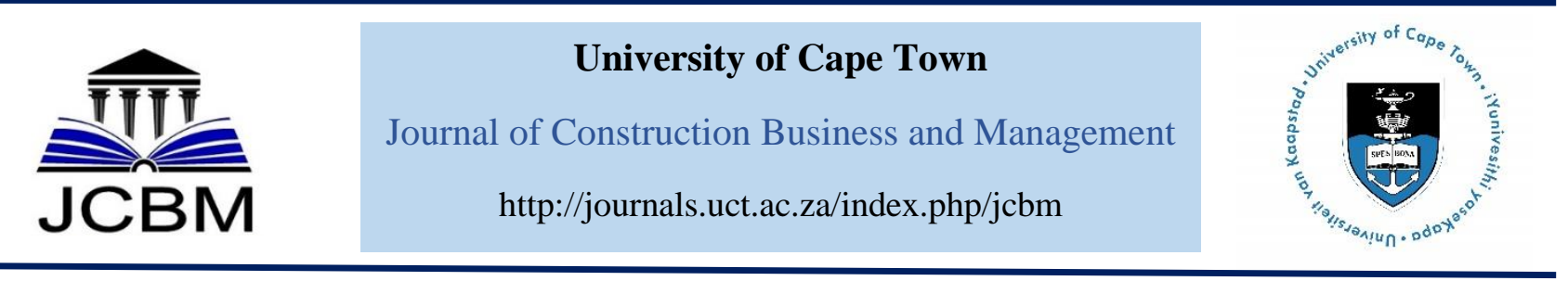

\title{
The Challenges of Closing Construction Projects Final Accounts in Botswana Local Authorities
}

\author{
J. K. Ssegawa ${ }^{1}$, P. D Rwelamila², and M.G. Mogome ${ }^{3}$ \\ 1 \& ${ }^{3}$ Faculty of Engineering and Technology, P. Bag 0061, Gaborone, University of Botswana \\ ${ }^{2}$ Graduate School of Business Leadership (GSBL), University of South Africa (UNISA)
}

Received 25 May 2019; received in revised form 18 January 2020; accepted 22 January 2020. https://doi.org/10.15641/jcbm.4.1.775

\begin{abstract}
Anecdotal information in the construction industry in Botswana indicated that the process of closing financial accounts for construction projects within a stipulated period is inefficient and ineffective. This is a serious industry problem because a project with an unclosed account is not a successful project as there are unfinished issues and claims left in abeyance to the detriment of both the client and contractor. This motivated a study aimed at investigating this aspect, including identifying the major causes of delays in formally closing final accounts of construction projects in local authorities. A multimethod approach consisting of a review of project documents which were beyond the end of the defect liability period were used in the study. Also, a questionnaire survey was administered to parties dealing with construction projects in the selected local authorities. Lastly, a focus discussion was held with key stakeholders who implement projects in some selected local authorities. Results indicated that while the final account closure process was inefficient (as only $42 \%$ of the accounts which were closed were finalised in the stipulated contractual time). Secondly, it was marginally effective (as only $54 \%$ of the sampled project accounts were closed). Common reasons for inefficiency and ineffectiveness include (i) contractors abandoning the project when they realise that the cost of rectifying the defects far exceeds the outstanding balance; (ii) clients taking too long to agree and approve final accounts; and (iii) loss of information when key personnel leave the project on the contractor's side before the final account is finalised. Despite the limitation of considering a selected number of local authorities' projects, the findings have confirmed anecdotal information circulating in the industry about the substantial numbers of project accounts that are usually left unclosed. The following recommendations based on the study results are made. That all adopted contract conditions be modified to focus on nipping the challenge in the bud as well as deterring instrument to future defaulters. The suggested modification: 'it shall be mandatory for contractors to bring the project under tender to a formal closure through final account documentation within a specified period, defaulting contractors to be blacklisted from future contract awards in Botswana LAs'. Ordinarily, since contractors can hardly suffer financial losses, the paper suggests that consultants and clients should objectively entertain contractors' claims arising from defects rectifications in the liability period. This is provided such defects were neither caused by poor materials nor are traceable to poor workmanship. These hopefully will mitigate the challenge if followed.
\end{abstract}

Keywords: Botswana, Construction projects, Final account, Local authorities, Project delays, Project management

\section{Introduction}

As a construction project comes to an end, a final account statement is prepared to signify three aspects. First, to indicate how the contract sum has been adjusted by additions, deduction, alterations and any other approved payments (Zakaria, Ismail and Yuso, 2012). Second, to indicate an agreement between the two main parties (i.e. client and contractor) to a construction project. Third, to signify an amicable separation of the two key parties. (Chi Ko, 2009). Generally, construction contracts contain a mechanism that allows a contractor, at a specified project milestone, to prepare and submit a final financial statement to a client for review and approval (HIKS,

\footnotetext{
${ }^{1}$ Corresponding Author.

Email address: rwelapmd@unisa.ac.za
} 
2012). In a perfect situation, where there are no disputes, the client is obliged by the contract to issue a final payment certificate and settle the final account. However, during this process, many issues that delay the closure of the final account usually arise. An example is a contractor deciding not to submit a draft final account statement on time or at all or the client not accepting the contractor's statement. An excerpt from the Botswana Department of Engineering and Building Services (DBES, 2017:16) an organ that manages the construction of building for the central government indicates how the closure of final accounts could be a problem:

'During 2010/11 and 2012/13 financial years, contractors listed below undertook the construction of various projects across the country which were implemented through DBES...The projects [listed] were never closed out in accordance with the provisions of the contracts at the end of the defect liability period....if there are any claims to be made you are required to produce all contractual documents relating to your project for consideration and other evidence normally required on a project before any claim, if any, can be considered. Contractors who fail to present themselves... after the said deadline, DBES will thereafter proceed with the process to close the accounts of these projects after which no further transactions will be possible in future'.

While best practice would encourage that accounts should be finalised as soon as it is contractually feasible, the excerpt indicates that first, the problem of failure to close accounts is real and can drag on for years. The projects were executed between the years 2010 and 2013, and five years (2017) later, the accounts were not closed. Second, though the monetary value of accounts was not disclosed (perhaps for confidentiality reasons), the total number of projects listed was 233. The number indicates the extent of the money that could be held in abeyance in project accounts. Third, the client was forced to rely on the Public Financial Management and Accountability Act (the Republic of Botswana, 2012) which is outside the project contract to close the accounts for contractors who were not forthcoming in closing the project accounts.

That background motivated a study to investigate the nature of closure of final accounts, particularly in local authorities in Botswana. The study had two objectives, first, to investigate the level of efficiency and
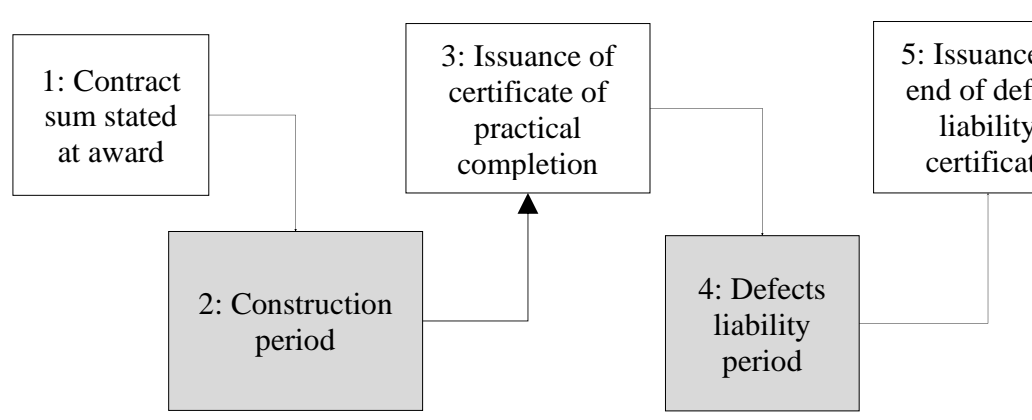

effectiveness in closing the final account of construction projects. Efficiency was viewed as the relative time that elapses for an account to be closed when compared to the time stipulated by the contractual clause. Effectiveness was viewed in terms of the ratio of the final accounts closed to the total, which should have been closed following contractual clauses. The second objective was to identify the major causes of delays in closing the final accounts as perceived by both the major stakeholders, i.e. clients and contractors. This paper, therefore, discusses findings thereof and is divided into four sections. The next section discusses a review of literature on final accounts, while the third section discusses the methodological approach used for the study. The fourth and fifth sections discuss the study findings followed by conclusions and recommendations.large.

\section{Contractual Parties, Clauses, Closure and Delay Factors in Final Account - Theory \& Practice}

Theory and practice relating to issues of final account was reviewed, and the resulting synthesis is discussed based on the key parties involved in the construction project, the closure process, contractual provisions concerning the research objectives.

\subsection{Main parties to the final account closure}

The key parties to the preparation, agreement and approval of the final account of a construction project are the client and contractor. Another party typically represents each, for example, quantity surveyor, architect, engineer or a combination of them. In terms of the final account, these two parties must agree that the final account statement represents what transpired during the construction period (El-Shaid, 2016; Kylindri et al., 2012).

\subsection{Processes leading to the final account}

As already noted earlier, the input for preparing starts from the moment the tender is awarded and a tender sum is agreed by the key parties. Figure 1 indicates four major project milestones $(1,3,5$, and 7$)$ and three activity periods $(2,4$, and 6$)$ between the milestones that feed into the drawing up a final account discussed as follows:

Source: Authors

Figure 1: Milestones and activities leading to construction project final account closure

\subsubsection{Construction period}

The genesis of the final account is the contract sum stated by the contractor at award (Box 1 of Figure 1) and accepted by the employer as the forecast cost towards the construction project. However, both parties know that this amount, for all practical purposes, will never be the exact 
final amount at the end of the construction period (Box 2). This is particularly more common in the two-tier negotiated contract system where several items are often incomplete in design at the time of tendering. Usually, several deductions and additions occur to the contract sum for various reasons; for example, the need to actualise the costs of the provisional items and prime costs. Clients too, often order work which was not stipulated in the contract and which inevitably changes the cost estimate. Therefore, due to these unavoidable changes during the project life, it is important to have an effective change control system that ensures that the contractor does not carry out changes believing they have been approved only to find out this is not the case (PMI, 2013; El-Shaid, 2016) and hence end up in a dispute. Good communication, documentation and record-keeping, especially by the contractor, are key aspects in having an effective change control system because these are easily auditable (RICS, 2015). Without a well-managed change control process, the final account negotiations may be protracted and difficult to manage.

\subsubsection{Defects liability period}

Practical completion milestone marks the end of the construction period as per the contract. As a sign of approval of this milestone, the client's agent issues a certificate of practical completion (Box 3) to the contractor to indicate that the project is officially complete and where possible may be occupied for beneficial use of the client (Kylindri et al., 2012). Practical completion does not always mean that all the work has been satisfactorily completed (CIDB, 2008). Therefore, the defects liability period (box 4) usually starts immediately after the issue of the certificate of practical completion. During this period, which is usually six or twelve months, depending on the type of contract, the contractor must make good, at his expense, all defects appearing in the permanent works reported by the client. In the event, the contractor fails to finish all defects identified in the period, which will not elapse until all the identified defects have been fixed to the satisfaction of the client (CIDB, 2008; Chi Ko, 2009). However, once the client is satisfied that all the works, including minor defects, have been rectified, the client may issue an end of defect liability certificate (Box 5) to the contractor (CIDB, 2008). The issuing of the final certificate means that the contractor is no longer responsible for any damages or defects that may occur to the building (Chi Ko, 2009; Kylindri et al., 2012). This, however, excludes latent defects, where the contractor may be liable for any major defects that manifest in the first five or ten years (depending on the contract conditions) after issuance of the final certificate (CIDB, 2008).

\subsubsection{Final account preparation stage}

Once the client issues the defect liability certificate (box $5)$, the onus is on the contractor to prepare and submit a draft final statement of account (box 6). However, best practice indicates that the contractor is at liberty to start at an early stage to prepare a statement leading to a draft final statement of account after receiving a certificate of practical completion (Box 3) from the client. Without repeating a subject well covered in various literature sources (e.g. RICS, 2015, Chi Ko, 2009), the contract sum may be adjusted by items that include, prime cost sums; provisional sums; payments to nominated sub-contractors or nominated suppliers; statutory fees paid by a contractor on behalf of the client; variations (design, quantity, quality, working conditions and sequencing of work). Others such as payments relating to the opening-up and testing of the works; resources price fluctuations; contra claims imposed as a result of the contractor's operations (such as a third-party claim resulting from contractor negligence or the contractual breach, for example, damaging screen wall of a neighbouring property); liquidated and ascertained damages; and release of any remaining retention.

\subsection{Contractual clauses relating to final account}

The processes relating to the final account is governed by the project contract and some aspects of common law (Chan, 2001; Chi Ko, 2009). There are several standard contract conditions used around the world including the Joint Contracts Tribunal (JCT), New Engineering Contract (NEC), Institution of Civil Engineers (ICE) and Fédération Internationale des Ingénieurs-Conseils (FIDIC). The local authorities in Botswana mainly use the FIDIC contract 1999 Edition, and an adapted form of the JCT contract hereafter referred to as local authority contract (LAC). In terms of Clause 14.11 of FIDIC' s Red Book, 1999 Edition, a contractor must within 56 days after receiving the performance certification submit the final statement of account as illustrated in Figure 2(a). On receipt of the final statement of accounts, the client must settle the account, if there is an agreement, within 28 days. Hence both contracts show that once the statement is verified and an agreement is reached, the client should issue a final statement to settle and close the account (Box 4 in Figure 1). On the other hand, Clause 26(f) of the LAC, states that a contractor must within 180 days after receiving the performance certification as illustrated in Figure 2(b) submit the final statement of account. On receipt of the final statement of account, the client must settle and close the account, if there is an agreement, within the same period. 
a) FIDIC

Contract

b) Local Authority

(LA) Contract
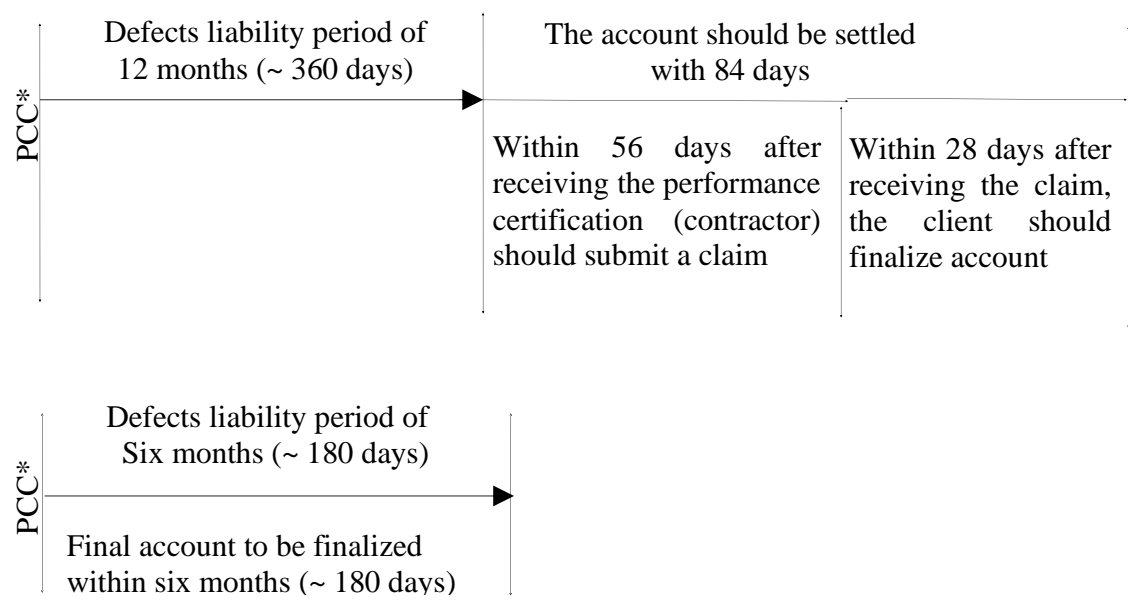

*PCC-Practical completion certificate

Source: Authors

Figure 2: Stipulations of FIDIC and LA clauses on the closure of construction projects

\subsection{Causes of delay in preparing the final account}

Factors affecting final account settlement are varied and inexhaustible. In general, it is the interpretation of the contract clauses; the efficiency at which the final account is prepared; the acknowledgement of the existence, adjustment and the valuation of work that fosters disputes and hence delays in closing the final account. Scholars (e.g. Zakaria et al., 2013; Chi Ko, 2009) have developed frameworks containing common themes indicating the major causes of delays in closing the final account: client- related, contractor-related, and other factors. These themes, together with other literature sources (e.g. OffeiNyako et al., 2016; Oseghale and Wahab, 2014), are summarised in Table 1. The factors are grouped into four categories, namely contractor, client, environmental and general factors. The general factors are caused by both clients and contractors, while environment-related factors result from issues not caused by neither the client nor the contractor.

Tale 1: Causes of delays in closing the construction project final Account

\begin{tabular}{|c|c|}
\hline Category of factors & Delay factors \\
\hline Client related & $\begin{array}{l}\text { - Client's inefficiency in promptly issuing the defect liability certificate } \\
\text { - Client's inefficiency in promptly assessing the FA } \\
\text { - } \quad \text { More work issued during the defects liability period which causes disagreements } \\
\text { - } \quad \text { Lack of funds to cater for the final payment }\end{array}$ \\
\hline Contractor Related & $\begin{array}{l}\text { - Contractor's inefficiency in promptly submitting an FA } \\
\text { - Too much workload leading to taking a long time to submit FA } \\
\text { - } \text { Contractors make errors in the FA and hence rejected } \\
\text { - } \quad \text { Inadequate experience of the contractor in preparing the FA and hence taking more time } \\
\text { - } \quad \text { Poor record keeping leading to loss of information to support claims } \\
\text { - Wrong documentation to support claims leading to back and forth submissions } \\
\text { - } \quad \text { High workload leading to 'I do not care attitude for an ending project.' } \\
\text { - Cost of rectifying the defects far exceeds the claim in the final account (FA) } \\
\text { - The contractor goes into liquidation or financial administration }\end{array}$ \\
\hline $\begin{array}{l}\text { Common to both the } \\
\text { client and contractor }\end{array}$ & $\begin{array}{l}\text { - Inadequate understanding of the contract conditions leading to disagreements } \\
\text { - Unsuitable contract to handle the complexities of project activities fostering disagreements } \\
\text { - } \quad \text { Tack of agreement with the work valuation method, process and hence value } \\
\text { - } \quad \text { Unethical client employees who may collude with contractors to defraud and which may lead to } \\
\text { protracted investigations. } \\
\text { - Poor change control mechanism leading disagreements of variations and other instructions }\end{array}$ \\
\hline Environment-related & $\begin{array}{l}\text { - } \quad \text { Change in regulations } \\
\text { - } \quad \text { Force majeure }\end{array}$ \\
\hline
\end{tabular}

Source: Zakaria et al. (2013); Chi Ko (2009); Offei-Nyako et al. (2016); Oseghale and Wahab (2014)

\section{Methodology}

A multimethod approach was used to achieve the objectives of the study, namely, review of project 
documents, questionnaire survey and a focus group discussion.

\subsection{A review of project records}

To investigate the extent to which construction projects remain unclosed in the final accounts, data were first sought from a sample of five drawn from a population frame of 16 local authorities' past contracts in Botswana. A non-probability sampling method (purposive sampling) was adopted. Authors knowledge of the research problem, expertise in project procurement systems in Botswana and LA's willingness to provide project data influenced their judgement in determining the sample (Martinez-Mesa, Gonzalez-Chica, Duquia, Bonamigo and Bastos 2016). Files of 132 practically completed projects were obtained from the five selected local authorities (LAs) and reviewed. Besides, only building construction projects which were beyond the contractually stipulated time for closing the project account and which were implemented in the period between 2013 and 2016 were selected. The period was chosen because the final accounts should have been due for finalisation, and it was thought the accounts would provide complete data for analysis. The scale in Table 2 was used to determine the efficiency and effectiveness of the final account closure process, based on the definition earlier stated.

Table 2: Scale for determining effectiveness and efficiency

\begin{tabular}{lc}
$\begin{array}{l}\text { Effectiveness \& efficiency } \\
\text { Scale }\end{array}$ & $\begin{array}{r}(\%) \text { of accounts closed - } \\
(\%) \text { of accounts closed } \\
\text { within time }\end{array}$ \\
\hline Highly effective/efficient & $75-100 \%$ \\
Effective/efficient & $50-74 \%$ \\
Ineffective/inefficient & $25-49 \%$ \\
Highly ineffective/inefficient & $0-24 \%$ \\
\hline Source: Adapted from
\end{tabular}

Source: Adapted from Bush and Burns (2010)

Apart from investigating the time delay in closing the final accounts, document review technique was used to scrutinise project documents in order to identify and understand the possible documented reasons why accounts could be unclosed. After scrutinising the records, it was felt that some of the behavioural reasons might not be documented on paper, for example, if the contractor lost supporting documents to the claim, the reason would not be documented.

\subsection{Questionnaire survey and focus group discussion}

To get a perception of the possible reasons for the delays in closing the final account, a questionnaire was administered to clients and contractors. Also, a focus discussion was held with eight project officers. The contractors declined to hold a focus discussion, while some claimed to be very busy. In contrast, others seemed to be suspicious of the survey participants' intentions despite the observation of ethical protocols.

The design of the questionnaire was adapted from some of the factors reviewed from existing and related literature shown in Table 1. Apart from seeking the background information on the respondents, the questionnaire had three sections; contributing factors by clients, contractors and general factors. The questionnaire contained common questions for both groups. It required respondents to indicate, based on their experience, whether a factor was perceived as frequently contributing to the delay in closing the final account. A Likert scale was used to rate the factors contributing to the delay of the closure of final accounts with the extreme ends of the scale being ...frequently contributed to the delay in closing the final account (5) and ...does not contribute at all to the delay in closing the final account (1). Internal reliability was conducted based on composite reliability (CR) to test the internal consistency of the questions. A total of 21 questions were included in the questionnaire, which had a score of 0.8 and above and three were dropped due to a lower test $(\alpha)$ score (scales not fit for purpose) (Peterson and Kim, 2013). Besides, each section ended with an open-ended question that provided respondents with an opportunity to state any other relevant aspects on the issue of final account closure. The validity of the Questionnaire was tested, and this is described in detail in Ssegawa, Rwelamila and Mogome (2019).

\subsection{Sampling technique}

Purposive sampling was used in sampling of LA representatives (clients) who were willing to participate in the study. A total of 48 officers agreed to participate in the study, but only 34 returned the completed questionnaires. An average of three categories of officers from each LA; architect, engineer and quantity surveyor completed the questionnaire.

\subsection{Questionnaire administration and response rate}

The ethical protocol was observed for both groups, especially in explaining the study purpose, seeking consent and voluntary participation in the study and ensuring anonymity for each participant. The entire data collection took a period of five months i.e. between July and December 2017. Collected data from project accounts, the returned questionnaires and focus group discussions were analysed on a spreadsheet.

The list of contractors was drawn from bidding documents in the selected LAs. A total of 289 contractors were identified, and questionnaires were distributed through fax, e-mail and drop-off. A total of 123 questionnaires were returned though 11 questionnaires were disregarded because the contractors had less than five years of industrial experience. The five years and above threshold were considered adequate to provide an insight into the research problem under investigation. The response rate was, therefore, $38.8 \%$ (112, i.e. used questionnaires), which was considered adequate for survey research (Ramshaw, 2018).

\subsection{Method of analysis}

The findings are discussed in two sections, the efficiency and effectiveness of the closure of final accounts and the causes of delay in the formal closure of a construction project in the final account. The scores of clients $(\mathrm{Cl})$ and contractors (Co) computed from participants' responses on the factors divided by the maximum composite agreement score (CGS) to normalise the scores using the following Equation 1. The (CGS) isolates factors having 
the highest scores agreement from the clients and contractors as the dominant causes of delays.

$C G S=\frac{\sum_{i=1}^{20} C l_{i} \times C o_{i}}{(C l \times C o)_{\max }}$

The $\mathrm{Cl}$ and Co responses for factors $\mathrm{i}=1$ to 20 , are divided by the maximum CGS in order to normalise the figures in percentages scores.

\section{Results and findings}

The discussion of results is centred on achieving the two objectives of the study, i.e. the efficiency/effectiveness of the closure of accounts and the perception held by the key stakeholders as to the causes of the delay of the process.

\subsection{Efficiency and effectiveness of the closure of final accounts}

Before a discussion of the findings on efficiency and effectiveness of the closure of final accounts commences, the profile of the projects which were selected for study is briefly highlighted to provide the context of the findings. 4.1.1 Profile of selected projects

Table 3(a) indicates that 132 projects were selected from five LAs, consisting of $69(52.3 \%)$ new developments and $63(47.7 \%)$ maintenance projects. FIDIC contracts were used for new developments and spanned 12 months or more while LA contracts were used for maintenance projects spanning a duration of up to six months. Table $3 \mathrm{~b}$ (i-iii) indicates that the median contract value for the sampled projects was P1, 048,320.00 (1US\$=BWP9.65 in January 2018). The highest and lowest contract values were P19, 641,038.60 and P330, 400.00 respectively for new and maintenance projects.

Table 3 (a)-(b): Profile of Selected Projects

\begin{tabular}{|c|c|c|c|}
\hline \multicolumn{4}{|c|}{ a) LAs' Projects } \\
\hline $\begin{array}{c}\text { Local } \\
\text { authority }\end{array}$ & $\begin{array}{l}\text { New developments } \\
\text { (FIDIC contracts) }\end{array}$ & $\begin{array}{l}\text { Maintenance } \\
\text { (LA contracts) }\end{array}$ & Total \\
\hline LA1 & 23 & 10 & 33 \\
\hline LA2 & 17 & 14 & 31 \\
\hline LA3 & 10 & 17 & 26 \\
\hline LA4 & 11 & 20 & 28 \\
\hline$\underline{\mathrm{LA} 5}$ & $\underline{8}$ & $\underline{6}$ & $\underline{14}$ \\
\hline$\underline{\text { Total }}$ & $\underline{69}$ & $\underline{63}$ & $\underline{132}$ \\
\hline Ratio & $52.3 \%$ & $47.7 \%$ & $100 \%$ \\
\hline \multicolumn{4}{|c|}{ b) The Financial Profiles of Projects } \\
\hline \multirow{3}{*}{\multicolumn{2}{|c|}{$\begin{array}{l}\text { i. Median contract value } \\
\text { ii. Maximum contract value } \\
\text { ii. Minimum contract value }\end{array}$}} & $\mathrm{P} 1,048,3$ & \\
\hline & & P19,641,038.60 & \\
\hline & & P330,400.00 & \\
\hline
\end{tabular}

\subsubsection{The effectiveness of final account closure}

Table 4 (a) shows that $72(54.4 \%)$ of the final accounts outs of 132 studied were closed. This indicates that LAs marginally effective (based on the scale given in Table 2) in closing the accounts. Table 4(b) shows that the amount of money held in unclosed final accounts (45.6\%) was P9, $401,115.10$. It is most probably that the amount will be higher if all sixteen LAs were studied. Also, since the value of contracts executed by LAs is often lower than that of, say, DBES, Department of Roads or Water Affairs, it means the value of unclosed final accounts may be enormous in the entire public construction sector of Botswana.

Table 4 (a)-(c): Level of effectiveness for closing final accounts

\begin{tabular}{lr}
\hline $\begin{array}{l}\text { a) State of final accounts of the } \\
\text { project studied }\end{array}$ & Proportion \\
\hline i) Closed accounts & $72(54.4 \%)$ \\
ii) Unclosed accounts & $\underline{60(45.6 \%)}$ \\
\end{tabular}

b) Amount held in the 60

P9,401,115.10 unclosed final account

\begin{tabular}{lc}
\hline c) Type of project involved & Proportion \\
\hline i) & $\begin{array}{l}\text { The proportion of } \\
\text { unclosed accounts } \\
\text { within the selected }\end{array}$ \\
& sample of maintenance \\
projects & \\
ii) $\begin{array}{l}\text { The proportion of unclosed } \\
\text { accounts within the } \\
\text { selected sample of } \\
\text { development projects }\end{array}$ & $\underline{32 / 69(46.4 \%)}$ \\
Total & $132(100.0 \%)$ \\
\hline
\end{tabular}

Table 4 (c) also indicates that the proportion of unclosed accounts $(71.1 \%)$ within the selected sample of maintenance projects is higher than the proportion of (46.4\%) of unclosed accounts within the selected sample of development projects. This could be because (i) maintenance jobs have many uncertainties, as the scope of work and quantities are difficult to determine during tendering and (ii) the frequent changes in the scope of work which always occur at the execution stage. Besides, because most maintenance jobs are of low value, they are carried out by small-sized contracting firms who are often newcomers in the industry and are characterised with inefficiency as lack of capacity (i.e. labour and equipment) and inexperience, particularly in estimates preparations. The preceding are most likely the reasons why projects are not officially closed when the costs of making good the defects exceed monies held as retentions.

\subsubsection{The efficiency of final account closure}

Further analysis was carried out on the 72 (54.4\%) projects for which accounts were formally closed, as shown in Table 4(a) to determine the level of efficiency using elapsed time. Figure 3 indicates that $42 \%$ (30) of the final accounts were closed in one month while the rest $(58 \%)$ were closed in periods beyond one month (with $27 \%$ being closed after six months and over). The longest period of closure was nine months and involved three projects. This result suggests that the final account closing regime is not efficient. This outcome reinforces the results indicated in Table 4 that the final account closure regime in the LAs is marginally effective, i.e. though more accounts by a simple majority were closed, most of them were closed beyond the stipulated time in the contract. 


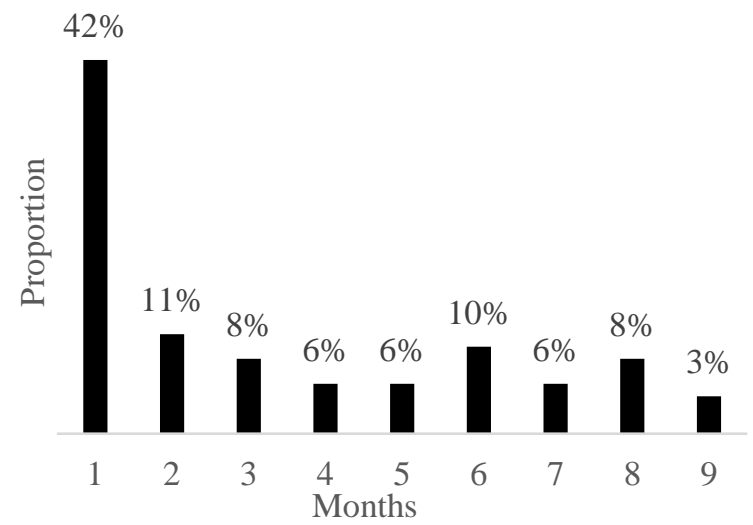

Figure 3: Time that elapsed before the final accounts were closed

When the project documents relating to these accounts were scrutinised, it was discovered that there were 21 cases where the contractor delayed in submitting the claim to the client. In the other 14 cases, it was the client who delayed in processing the final account. Furthermore, there were 12 cases where the contractor was given additional work during the defects liability period. This essentially amounted to extending the contract period and hence the final account settlement period. There was also an interesting scenario in one of the LAs that had 11 projects, the client's representative grouped the final account claims to process in one month (e.g. in April and December). Some of the projects took a long time to process while others were processed in a shorter period. Though researchers did not interrogate the officer as to why this was done, it demonstrates a convenience to process all accounts at once than anything else. Lastly, it is noteworthy that several cases had more than one reason for the delay.

4.1.4 Age of unclosed accounts

The unclosed final accounts of $60(45.6 \%)$ projects (see Table 4) were scrutinised. Figure 4 indicates that $40 \%$ of them had remained unclosed for less than a year while the majority $(60 \%)$ of the project accounts had remained unclosed for more than one year. Moreover, four $(7 \%)$ projects' final accounts had remained unclosed for three years. On scrutinizing the documents from this group, it was noted that most of these unclosed projects were of maintenance types that were executed by mostly small (class OC\& A) and medium contractors (class B). The documents of these projects contained some insightful correspondences which indicated some kind of disputes, for example, one of such correspondence read '... according to the terms of reference, the aspects which you refer to in your communication dated... were not included or even referred to ......It would be prejudicial to us to expect them to be carried out without adequate compensation...' As Canter (1993) and Lai \& Yik (2007) noted, maintenance contracts contain many uncertainties due to lack of precisions in the work estimates. Such are usually the potential causes of disputes and eventually delays in the final reconciliations. The rest of the projects had two symptomatic reasons why they had not been closed either the contractors were 'dragging their feet' to rectify the defects or had simply not attended to the defects despite notification. The actual reasons were not documented and why it was necessary to augment document review with a survey of both the client and contractor perceptions.

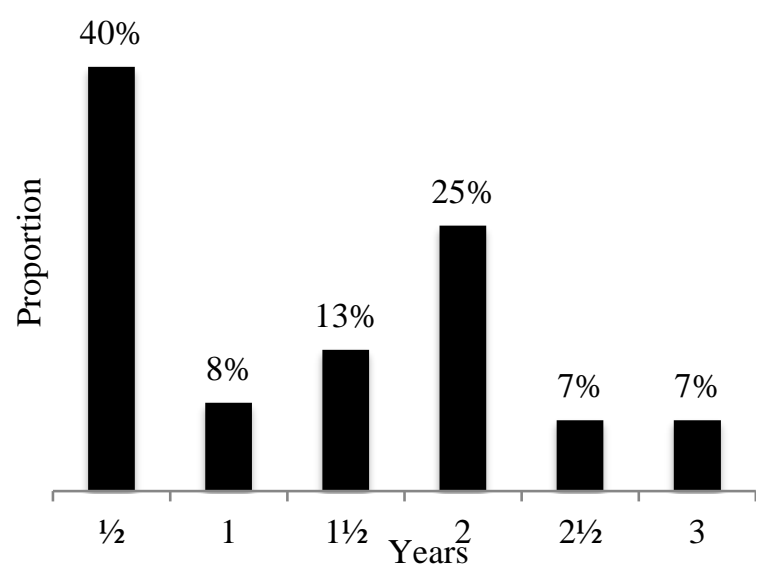

Figure 4: Age of unclosed final accounts

\subsection{Causes of Delays for Closing the Final Accounts}

A discussion of the causes of delays for closing the final accounts is preceded by a brief description of the profile of respondents to underscore their capacity to provide an in-depth insight into the topic of investigation.

4.2.1 Profile of respondents

A total of 166 questionnaires were analysed consisting of 34 clients' representative and 132 contractors (who had worked for any of the five LAs within the period under review).

Table 5 (a)- (d): Profile of respondents

\begin{tabular}{|c|c|c|}
\hline \multicolumn{3}{|c|}{$\begin{array}{l}\text { a. The profession of client representatives (drawn } \\
\text { from } 5 \text { LA) }\end{array}$} \\
\hline & No. & Ratio \\
\hline $\begin{array}{l}\text { Quantity } \\
\text { surveyors }\end{array}$ & 11 & $32 \%$ \\
\hline Engineers & 13 & $38 \%$ \\
\hline Architects & $\underline{10}$ & $30 \%$ \\
\hline Total & $\overline{34}$ & $100 \%$ \\
\hline \multicolumn{3}{|c|}{ b. Client representatives' experience } \\
\hline Years & No. & Ratio \\
\hline $5-10$ & 10 & $29 \%$ \\
\hline $11-19$ & 14 & $41 \%$ \\
\hline $20-29$ & 7 & $21 \%$ \\
\hline 30 and over & $\underline{3}$ & $9 \%$ \\
\hline Total & $\underline{34}$ & $\underline{100 \%}$ \\
\hline \multicolumn{3}{|c|}{ c. Class of contractors } \\
\hline & & \\
\hline Small (OC \& A) & 48 & $36 \%$ \\
\hline $\begin{array}{l}\text { Medium (B \& } \\
\text { C) }\end{array}$ & 76 & $58 \%$ \\
\hline Large (D \& E) & $\underline{8}$ & $6 \%$ \\
\hline & 132 & $100 \%$ \\
\hline \multicolumn{3}{|c|}{ d. Contractors' experience } \\
\hline Years & No. & Ratio \\
\hline $5-10$ & 14 & $11 \%$ \\
\hline $11-19$ & 74 & $56 \%$ \\
\hline $20-29$ & 32 & $24 \%$ \\
\hline 30 and over & $\underline{12}$ & $9 \%$ \\
\hline Total & $\overline{132}$ & $100 \%$ \\
\hline
\end{tabular}


Table 5(a) shows there was a right mix of the built environment professionals (quantity surveyors, engineers, and architects) from each LA. Table 5(b) indicates that a small number (29\%) of client representatives had industry experience of 10 years and below while the majority (71\%) had experience stretching from 11 years to over 30 years. Table $5(\mathrm{c})$ indicates majority $(58 \%)$ of the contractors are in the medium category (class B\&C), followed by (36\%) the small category (class OC \& A) and a few $(6 \%)$ in the large category (Class D\&E). This was commensurate with the value of building projects undertaken by local authorities. Table 5(d) further indicates that the majority $(89 \%)$ of the respondents had substantial experience in the industry of 11 years and above. The profile of respondents indicates that they could provide valuable insights into the causes of delays in closing the final account.

Table 6: Causes of delay in closing final accounts

\subsubsection{Causes of delay in closing the project in the final account}

The mean responses (including computed composite scores) by contractors and clients regarding causes of delay in closing the final account are summarised in Table 6. It can be seen from the Table that opinions of the clients and contractors differ on the factors' impact on the delay in closing a project in the final account. For example, the client indicated with a score of 4.70 that it is the 'contractor's lack of timely preparation and submission of draft final account to client' that is significant in causing the delay. Contractors had a contrary view with a score of 1.21. Similarly, Table 6(b), it is the contractors' opinion that 'client's failure to understand or misinterprets the contract conditions' is a significant delay factor in closing a project in the final account. Contractors are of the contrary opinion on the factor's level of impact on the delay.

\begin{tabular}{|c|c|c|c|c|}
\hline \multirow[b]{2}{*}{ Delay factor } & \multicolumn{2}{|c|}{ Response Rating } & \multicolumn{2}{|c|}{ Composite Score } \\
\hline & $\begin{array}{c}\text { Client } \\
\left(\mu_{\mathrm{cl}}\right)\end{array}$ & $\begin{array}{c}\text { Contractor } \\
\left(\mu_{\mathrm{c} 0}\right)\end{array}$ & $\left(\boldsymbol{\mu}_{\mathrm{cl}} \mathbf{X} \boldsymbol{\mu}_{\mathrm{c} 0}\right)$ & $\begin{array}{c}\text { Normalised } \\
(\%)\end{array}$ \\
\hline \multicolumn{5}{|l|}{ a. Contractor - related factors } \\
\hline $\begin{array}{l}\text { 1. Contractor's lack of timely preparation and submission of draft final } \\
\text { account to the client }\end{array}$ & 4.70 & 1.21 & 5.69 & $42 \%$ \\
\hline 2. Lack of understanding of the contract conditions by the contractor & 4.53 & 1.67 & 7.57 & $56 \%$ \\
\hline 3. Delay in submission of accurate claims by the contractor. & 4.40 & 1.74 & 7.66 & $57 \%$ \\
\hline 4. Contractor's failure to agree to the valuation of work. & 4.13 & 1.24 & 5.12 & $38 \%$ \\
\hline $\begin{array}{l}\text { 5. Submission of inadequate documentation supporting the claim by } \\
\text { the contractor (even where they exist) }\end{array}$ & 4.13 & 1.83 & 7.56 & $56 \%$ \\
\hline $\begin{array}{l}\text { 6. Poor records keeping by the contractor leading to a lack of } \\
\text { supporting documents for the claim }\end{array}$ & 4.07 & 1.52 & 6.19 & $46 \%$ \\
\hline 7. Errors in the claim submitted by the contractor & 4.00 & 1.48 & 5.92 & $44 \%$ \\
\hline 8. An inadequate experience by the contractor in the valuation of work & 3.93 & 1.60 & 6.29 & $47 \%$ \\
\hline $\begin{array}{l}\text { 9. The person in charge of final account is retired, dead or transferred } \\
\text { from project or workstation. }\end{array}$ & 3.73 & 2.52 & 9.40 & $70 \%$ \\
\hline $\begin{array}{l}\text { 10. The workload from other projects by the contractor and hence not } \\
\text { being able to prepare and submit a draft final account to the client. }\end{array}$ & 3.67 & 2.20 & 8.08 & $60 \%$ \\
\hline 11. Cost of rectifying the defects far exceeds the outstanding balance & 3.60 & 3.74 & 13.46 & $100 \%$ \\
\hline \multicolumn{5}{|l|}{ b. Client - related factors } \\
\hline 12. Failure by the client to understand the contract conditions. & 1.60 & 4.71 & 7.54 & $56 \%$ \\
\hline 13. Lack of adequate available funds for the project by the client. & 1.20 & 4.62 & 5.54 & $41 \%$ \\
\hline 14. Client taking a long time to agree and certify the claim. & 2.60 & 4.48 & 11.65 & $87 \%$ \\
\hline $\begin{array}{l}\text { 15. The person in charge of final account from the client's side is } \\
\text { retired/dead/disappear or transferred from project or workstation. }\end{array}$ & 1.73 & 4.43 & 7.66 & $57 \%$ \\
\hline 16. Poor financial management by the client. & 1.53 & 4.38 & 6.70 & $50 \%$ \\
\hline $\begin{array}{l}\text { 17. Lots of extra work issued by the client during Defects Liability } \\
\text { Period which brings up disputes }\end{array}$ & 1.53 & 4.24 & 6.49 & $48 \%$ \\
\hline \multicolumn{5}{|l|}{ c. Contractual provisions-related factors } \\
\hline $\begin{array}{l}\text { 18. Contract conditions biased to one party which eventually bring } \\
\text { disputes and hence affect the final account }\end{array}$ & 1.20 & 4.26 & 5.11 & $38 \%$ \\
\hline 19. Contract used is not comprehensive to guide the final account & 1.47 & 4.07 & 5.98 & $44 \%$ \\
\hline 20. Contract used is too complicated to be understood by both parties. & 1.53 & 3.76 & 5.75 & $43 \%$ \\
\hline
\end{tabular}

Lack of disagreement relating to the challenges that face the construction industry in Botswana is not a new phenomenon. An earlier study observed that there is always a blame game between the service providers and the clients (BOCCIM, 2008). However, the same study concluded that both parties share responsibility in the sector's challenges. The above results indicate that both parties contribute to the delays in closing the final account.

Figure 5 shows that nine factors have CGS normalised percentage score of more than $50 \%$. However, four factors which had a higher CGS percentage score of $60 \%$ and above were considered the major causes of delay in closing the accounts. These are: 
i) cost of rectifying the defects far exceeds the outstanding balance (13.46 or $100 \%)$

ii) the client takes longer time to agree and certify the claim (11.65 or $87 \%$ )

iii) the person in charge of final account (for the contractor) is retired, transferred, resigns or dies from project or workstation $(9.40$ or $70 \%)$.

iv) The workload from other projects makes the contractor unable to prepare and submit a final account to the client $(8.08$ or $60 \%)$.
It is interesting to note that researches on the impact of 'Contractor's failure to agree to the valuation of work' on delay in construction project finalizations in the final account (see item 4 in Table 6), is sparse. However, it has in this study composite and normalized percentage scores of 5.12 ad $38 \%$, the factor by name, is suggestively a cause of delay in final account preparation.

Failure by the client to understand the contract conditions.

Submission of inadequate documentation supporting the.

Lack of understanding of the contract conditions by the.

Delay in submission of accurate claims by the contractor.

Person in charge of final account from the client's side.

Work load from other projects by the contractor and.

Person in charge of final account is retired, dead or.

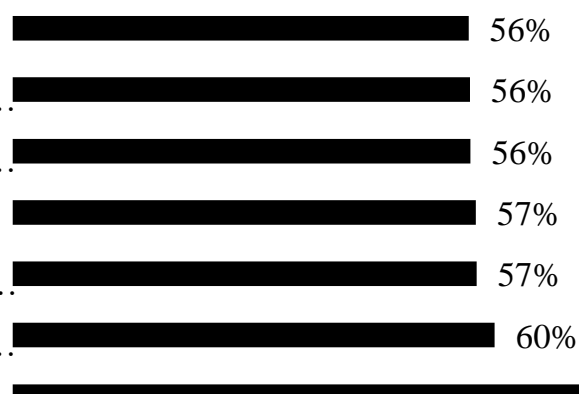

Client taking longer time to agree and certify the claim.

Cost of rectifying the defects far exceeds the.

Figure 5: Significant delay factors in construction project closing in the final account

The first set of factors can be corroborated with the findings from document review, where several contractors abandoned sites without further communication despite correspondences from clients. The second set indicates that clients also contributed to the delays while both parties cause the third factors. Other factors alluded by BOCCIM (2008) indicated that contractors, especially those in the medium and small categories, sometimes take jobs above their carrying capacity, moreover, in different locations of the country. The study further noted that they prioritise jobs; therefore, a job which is supposed to be at completion stage may be of a lower priority than that which must commence soon or an on-going job which must not be delayed.

\subsection{Discussion of findings}

The findings indicate that there is low efficiency (42\%) and marginal effectiveness $(54.4 \%)$ in closing the accounts. Chi Ko (2009) noted that the challenges of backlogs in settlement of final accounts are a result of the actions and inactions of either party. For a project account to remain unclosed for a long time (or sometimes forever) has many implications. First, it shows the project is not entirely successful as there is an aggrieved party who could be the client or contractor (Cheung et al., 2000). Secondly, the contractor's cash flow is reduced as money tied in the final account in the form of a claim or retention. For the clients, the money stays in abeyance in project accounts when it could have been used on other developments. It could be 'held-up' in a client's account for five years as stipulated by the Public Financial Management and Accountability Act of Botswana (the Republic of Botswana, 2012). In a focus discussion, the project officers intimated that it is difficult to determine the contracts on the projects of contractors who abandon their jobs. They noted that in some instances, they are politically connected such that the politicians interfere with decisions to terminate their contracts or to blacklist the contractors. Ntshole (2014) also, noted that terminations of contracts and hiring a new contractor eventually do not work in favour of the projects. That is why the Department of Engineering and Building Services, for instance, relied on the Financial Management and Accountability Act which allows sums not claimed within five years to be returned to the consolidated fund. Tighter contract conditions are therefore needed that incorporates explicitly the clause that a contractor who abandons the site without addressing the defects after the defect liability period, the client reserves the right to engage another contractor to rectify the defects, be paid from the withheld money and if not enough, the client should claim the balance from the contractor through legal channels (Ntshole, 2014). Lastly, the time lapses make it difficult to get to terms with the issues that caused the delay or disputes, for example, key personnel who had the information on the case on either side might have left their employment. Such situations lead to costly, time-consuming, undesirable and protracted negotiations, arbitrations or ligations.

\section{Limitations of the study}

Despite the inherent limitations of data sourced from only five out of the sixteen LAs in Botswana, it nevertheless provides a useful insight into the challenges of closing a construction project in the final account.

\section{Conclusions}


Project closing in the final account is the finalisation of a project and indicates an agreement between the contractor and the client on the project activities and associated financial history. The agreement on the contents and closure of the final account is one of the indicators of project management success because it brings an amicable closure to the contract.

The study indicated that the closure process based on the sampled projects in the five selected LAs was marginally effective as there were $54.4 \%$ of the accounts closed. Secondly, for those which were closed, the process was inefficient as only $42 \%$ of the accounts were closed within one month of the stipulated contractual terms. For unclosed accounts, it meant that money is tied up, which could have been used by the contractors or clients; for example, over P9.4 million was held in unclosed accounts. Three significant causes of delay in the closing of the construction project final account within the stipulated clauses of contract conditions were found in the study. First, contractors sometimes find the cost of rectifying the defects far exceeding the outstanding balance, they, therefore, abandon the projects and hence never submit final account. Secondly, the clients also take longer time to agree and certify the final claims. Thirdly, in the contracting firms, there are situations where persons in charge of final account retire, resign or die. Project information is, therefore lost or takes a while to assemble. Contractors and clients, therefore, called to improve on the fulfilment of their contractual responsibility by deliberate plans for increases in the efficiency and effectiveness of final account closures.

The fact that most of the modern standard forms of contracts in various countries (including Botswana) contain provisions upon which the engineer, the architect, quantity surveyor, cost engineer and project manager are obliged to settle the final account and issue a final payment certificate, actively strengthens the importance of a project schedule and projects cost parameters. Since a successful project is measured based on achieving positive results for all project parameters, including meeting a project schedule and budget, failure to settle the final account and issue a final payment certificate, point to the failure of meeting project schedule and cost requirements (budget), thus a clear outcome of project failure. It should be acknowledged that failure to settle the final account of a project strongly signify poor management of construction projects.

\section{References}

BOCCIM (2008), Report on the Study to Improve the Performance of the Construction Industry in Botswana, University of Botswana, Gaborone, Botswana.

Burns, A. C. and \& Bush, R F. (2010), Marketing Research, 6ed, Pearson, Saddle River, New Jersey.

Canter (1993), Resource Management for Construction: An Integrated Approach, Palgrave MacMillan, Basingstoke, United Kingdom

Chan, P, C, A., (2001), Framework for Measuring Success of Construction projects. Construction Project Delivery Strategies, School of Construction Management and Property, Queensland University of Technology, Brisbane.

\section{Implications of the research findings}

Since half of the construction projects executed by the Botswana LAs are found not to formally close in final accounts, it implies that: (i) references cannot be correctly made to many past project costs in Botswana as certain works and values are not concluded; and (ii) past references and use of cost figures of construction projects for example in approximate or preliminary estimates have been in error and information derived might have misled the users.

\section{Recommendations}

Based on the drawn inference that only the contractors who discovered that retention monies would not be enough to rectify the defects in compliance with the contract condition clauses on liability, the paper recommends that all adopted contract conditions be modified to focus on nipping the challenge in the bud as well as deterring instrument to future defaulters. The suggested modification: 'it shall be mandatory for contractors to bring the project under tender to a formal closure through final account documentation within a specified period, defaulting contractors to be blacklisted from future contract awards in Botswana LAs'. Ordinarily, since contractors can hardly suffer financial losses and to be fair to other stakeholders, the paper suggests that consultants and clients should objectively consider contractors' claims arising from defects rectifications in the defect liability period. This is provided such defects were neither caused by poor materials nor are traceable to poor workmanship. These hopefully will mitigate the challenge if followed.

\section{Area of further studies}

Furthermore, this paper suggests that the study be upscaled to include the rest of the LAs and other project management entities, for example, housing, water and roads in Botswana, to confirm the results of the study.

Cheung, S. O., Tam, C. M., Ndekugri, I. and Harris, F. C. (2000), Factors affecting clients' project dispute resolution satisfaction in Hong Kong, Construction Management and Economics, 18 (3), 281-294.

Chi Ko, K., (2009), Study of important factors affecting final account settlement satisfaction of Hong Kong Civil Engineering Projects: Contractor's Perspective, Unpublished Doctoral Thesis, City of Hong Kong University, Hong Kong.

CIDB (2008), Basic Guide General Conditions of Contract for Construction Works (GCC 2004). Construction Industry Development Board. South African Institution of Civil Engineering. 
DBES (2017), Public Notice- Ministry of infrastructure and housing development closeout of contracts, Daily News, Government Printer, Gaborone.

El-Shaid, M. A. (2016), Final accounts procedures for construction projects, available at https://www.linkedin.com/pulse/final-accountprocedures-construction-projects-mina-anis, (accessed on 4 July 2017)

HIKS (2012), Practice notes for quantity surveyors: Final account, The Hong Kong Institute of Surveyors, available at http://www.academia.edu/6307658/practice_notes_for_q uantity_surveyors_Final_Accounts, (accessed on 14 July 2017)

Kylindri, G., Blanas, L., Henriksen and Stoyan, T., (2012), Measuring Project Outcomes: A Review of Success Effectiveness Variables, in Proceedings of 7th Annual MIBIS International Conference, 212-223.

Ntshole, T. (2004), Companies fail to collect retentions, Daily News: available at http://www.dailynews.gov.bw/mobile/newsdetails.php?nid $=11925 \&$ flag $=$

Offei-Nyako, K., Tham, L.C. O., Bediako, M., Adobor, C. D. and Asamoah, R. O. (2016), Deviations between Contract Sums and Final Accounts: The Case of Capital Projects in Ghana, Journal of Construction Engineering, 2016, available at http://dx.doi.org/10.1155/2016/2814126 (accessed on 19 July 2017)
Oseghale, G. E. and Wahab, A. B. (2014), Analysis of relationship between preliminary estimate, tender sum and final accounts: A case study of selected building projects in Edo State, Nigeria, Journal of Civil and Environmental Research, 6(6), 76, 2014

Peterson, R. A., \& Kim, Y. (2013), On the relationship between coefficient alpha and composite reliability, Journal of Applied Psychology, 98(1), 194-198.

PMI (2013), Project Management Body of Knowledge, Project Management Institute (PMI), Pennsylvania, USA,

Ramshaw, A. (2018), The Complete Guide to Acceptable Survey Response Rates, Genre, available at https://www.genroe.com/blog/acceptable-surveyresponse-rate-2/11504 (accessed on 18-12-2018)

Republic of Botswana (2012) The Public Finance Management Act, Republic of Botswana, Government Printer, Gaborone.

RICS (2015), Final account procedures, Royal Institute of Chartered Surveyors (RICS), London.

Zakaria, Z., Ismail, S., and Yuso, A., M. (2012), Cause and Impact of Dispute and Delay the Closing of Final Account in Malaysia Construction Industry, Journal of Southeast Asian Research, 1 - 12.

Ssegawa, J. K., Rwelamila, P. D. and Mogome, M. G. (2019). Challenges of Closing Construction Projects Final Accounts - the case of Local Authorities in Botswana, Unpublished Research Report, Department of Civil Engineering, University of Botswana, Gaborone. 